\title{
Water Conservation Service Assessment and Its Spatiotemporal Features in National Key Ecological Function Zones
}

\author{
Jun Zhai, ${ }^{1}$ Yuping Liu, ${ }^{1}$ Peng Hou, ${ }^{1}$ Tong Xiao, ${ }^{1}$ and Guangzhen Cao ${ }^{2}$ \\ ${ }^{1}$ State Environmental Protection Key Laboratory of Satellite Remote Sensing, Satellite Environment Center, \\ Ministry of Environmental Protection of the People's Republic of China, Beijing 100094, China \\ ${ }^{2}$ Key Laboratory of Radiometric Calibration and Validation for Environmental Satellites, China Meteorological Administration, \\ National Satellite Meteorological Center, Beijing 100081, China
}

Correspondence should be addressed to Peng Hou; houpcy@163.com and Guangzhen Cao; caogz@cma.gov.cn

Received 8 March 2016; Revised 11 July 2016; Accepted 1 August 2016

Academic Editor: Dong Jiang

Copyright (C) 2016 Jun Zhai et al. This is an open access article distributed under the Creative Commons Attribution License, which permits unrestricted use, distribution, and reproduction in any medium, provided the original work is properly cited.

In order to improve ecosystem service and protect nation ecology security, the government had designated lots of important ecosystem service protection areas, named national key ecological function zones (NKEFZ) in China. Water conservation service had been assessed with the help of multisource remote sensing data, and spatiotemporal features were analyzed from 2000 to 2014 in these ecological services zones. By assuming precipitation scenario as the constant, contribution for water conservation from human activities and climate change was analyzed, and result shows that, because of vegetation restoration by human activities, evapotranspiration increased obviously with the increase of the vegetation coverage. This could reduce the water conservation. However, actual annual increase of water conservation mainly comes from the increase of precipitation. Our analysis revealed that the choice of evaluation model played a decisive role in the reason analysis, which would affect the development of ecological policy.

\section{Introduction}

Water conservation service, as one of the most important terrestrial ecosystem services, is a comprehensive feature of ecological function by water, soil, and vegetation interactions. Vegetation is the main source of water conservation service in terrestrial ecosystem. The vegetation growth and change characteristics could reflect water conservation ability. At present, small watershed research about water conservation is relatively mature. The main research methods include field observation, statistical analysis, and watershed simulation models [1-3]. However, the assessment methods extrapolation from watershed scale to regional scale of ecosystem water conservation service is still facing great challenges. The main reason is that traditional hydrological models could not quantify the water conservation effects of ecosystem changes, especially in region with complex underlying surface, such as the land management planning or ecological protection project regions [4, 5]. In addition, less study cases quantitatively decompose the influence of ecosystems and ecological services from human activities and climate. This limits us to devise targeted management measures and implement differentiated protection projects in different ecological regions.

National key ecological function zone (NKEFZ) is the important region of ecosystem service and national ecological security. The purpose of this policy is to restore and improve the regional ecological function of water conservation, soil and water conservation, windbreak and sand fixation, and biodiversity maintenance $[6,7]$. NKEFZ planning had been considered in the natural ecosystem service factors and social economic factors and had formed regional function index and regionalization scheme [8]. Therefore these zones are also the demonstration area of harmonious coexistence of human and nature. NKEFZ is an important basis of regional ecological compensation, transfer payment, and delineation of ecological protection redline regions $[6,9]$. At present, related research mainly focuses on ecological service assessment in a single zone $[10,11]$. Cases about dynamic assessment in temporal and spatial variation and the 


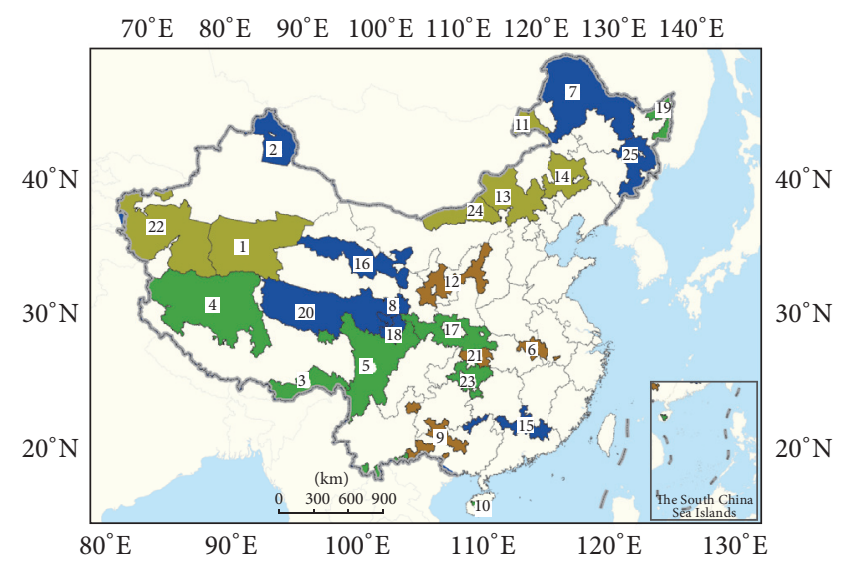

Types of national key function zones

Water conservation

$\square$ Water and soil conservation

$\square$ Wind break and sand fixation

$\square$ Biodiversity maintenance

-.... Provincial boundaries

Figure 1: Distribution and location of national key ecological function zones: 1: grassland desertification control region in Arkin (GA); 2: mountain forest steppe region in Altai (MA); 3: forest region in the edge of southeastern Tibet (FT); 4: desert region of Qiangtong Plateau in the northwestern Tibet (DT); 5 : forest and biodiversity in Sichuan and Yunnan (FY); 6: soil and water conservation region in Dabie Mountain (SM); 7: forest region in greater and lesser Hinggan Mountains (FM); 8: important water supply region of the Yellow River in Gannan (IG); 9: karst rocky desertification region in Guangxi, Guizhou, and Yunnan (KY); 10: tropical rainforest region of central Hainan Island (TI); 11: grassland meadow region in Hulun Buir (GB); 12: hilly and gully region of Loess Plateau (HP); 13: Hunshandake desertification region (HD); 14: grassland desert region of Horqin $(\mathrm{GH})$; 15: forest and biodiversity region in Nanling Mountain (FNM); 16: glacier and water conservation region in Qilian Mountain (GM); 17: biodiversity region in Qinba (BQ); 18: grassland wetland region of Ruoergai (GR); 19: wetland region of Sanjiang plain (WS); 20: grassland meadow wetland region in Sanjiangyuan (GS); 21: Three Gorges Reservoir Area (TA); 22: desertification control region of Tarim River (DR); 23: biodiversity, soil conservation region in Wuling Mountains (BW); 24: grassland region in Yinshan Mountain (GYM); 25: forest region in Changbai Mountain (FCM).

whole NKEFZ are rare, especially before the implementation of the ecological project and transfer payment. It is not helpful for scientific judgment of the following ecological compensation measures and engineering implantation [12].

Most NKEFZ are in the source area of river and basin and are distributed in different climatic zones. Various ecosystems had undergone significant changes in the impact of climate change and human activities in these regions $[12,13]$. Hydrological balance and the cycle process, which could impact the ecological service, had also changed dramatically. In this paper, multisource satellite remote sensing data and ground observation data were used to evaluate the ecosystem and water conservation service in the NKEFZ during 2000-2014. Spatiotemporal features were analyzed with the help of spatial statistics, time series analysis, and simulation scheme comparison. Finally, this paper attempted to identify the impact difference between human activities and climate change.

\section{Study Area}

NKEFZ includes 25 regions, as Figure 1 showed [7]. Total area of NKEFZ is about $3.86 \times 10^{6} \mathrm{~km}^{2}$, accounting for $40.2 \%$ of national land area. In these regions, population is about 0.11 billion, accounting for $8.5 \%$ of total population of China. According to the leading ecological service, there are four types of national key ecological services, including water conservation, water and soil conservation, wind break and sand fixation, and biodiversity maintenance (Figure 1).

\section{Data Sets}

Land use and land cover change data on the NKEFZ from 2000 to 2014 with spatial resolution in $30 \mathrm{~m}$ were determined following the standardized methodology outlined in $[14,15]$. A hierarchical classification system with 25 types of land use and land cover classes were further grouped into 6 aggregated classes consisting of farmland, forest, grassland, water bodies, built-up areas, and unused land. The comprehensive accuracy was more than 90\% [14-17]. Then the land use and land cover change data are classified as farmland, forest, grassland, water body and wetland, settlement, and bare land ecosystems correspondingly. Spatial statistics tools were used to evaluate the characteristics of ecosystem area comprehensively.

Gridded data set of temperature and precipitation data was assembled from the National Meteorological Information Center of China Meteorological Administration. This data set was generated based on the basic meteorological elements of the 2742 National Ground Meteorological Stations; the TPS (Thin Plate Spline) combined with threedimensional geospatial information was used for spatial interpolation. The spatial resolution of the data set is $0.5 \times$ 0.5 degrees. The boundary of the NKEFZ was used to extract the data needed for this study.

Normalized difference vegetation index (NDVI) was used to reflect the growth and changes of ecological quality in study regions. NDVI data were extracted from the month MODIS vegetation indexes product (Collection 5 MOD13Q1, $250 \mathrm{~m}$ spatial resolution, 16-day composites) [18] within the NKEFZ. Data smoothing method based on the SavitzkyGolay filter was used to smooth out noise from cloud and atmosphere in NDVI time series $[19,20]$. Annual mean NDVI values were used to reflect interannual variation of vegetation.

\section{Methods}

4.1. Water Conservation Service Assessment. Because of difference between the NKEFZ and watershed, soil water holding capacity change is very small in climate normal years $[21,22]$. In this article, the water yield in pixel scale, which was calculated by precipitation minus evapotranspiration, was used to quantitatively describe the water conservation service capacity. The calculation method is as follows:

$$
\mathrm{WR}=P-\mathrm{ET} .
$$


Precipitation was spatial gridded data generated from meteorological stations observation data interpolation. The actual evapotranspiration data was calculated from MODIS satellite observation data by Penman-Monteith formula [23, 24]. The accuracy evaluation based observation flux data indicated that the product was suitable for regional scale evapotranspiration analysis [23-26]. At present, ecological protection projects had been implemented in some ecological function zones. Different contribution between human activities and climate change was considered by calculating the water conservation (WR) in two schemes: (1) To describe the impact combined ecological protection project and climate change factor, WR of observation was calculated with precipitation of every year. (2) To describe the impact mainly from human activities, like ecological protection projects, WR of simulation was calculated with mean annual precipitation.

4.2. Trend Analysis. The unitary linear regression can be used to estimate the water conservation trend at pixel scale according to the Ordinary Least Squares (OLS). In this study, python was used to calculate the slope. ArcGIS10.2 software was used to show the spatial distribution of raster data. The slopes were calculated as follows:

$$
\text { Slope }=\frac{\sum_{i=1}^{n} m_{i} X_{i}-(1 / n) \times \sum_{i=1}^{n} m_{i} \times \sum_{i=1}^{n} X_{i}}{\sum_{i=1}^{n} m_{i}^{2}-(1 / n) \times\left(\sum_{i=1}^{n} m_{i}\right)^{2}}
$$

where $X_{i}$ is the value of water conservation in year $i, i=$ $1,2,3, \ldots, n . m_{i}$ is the number of the year in sequence, and $m_{1}=1, m_{2}=2, m_{3}=3, \ldots, m_{n}=n$, in which $n=15$.

\section{Result and Discussion}

5.1. Ecosystem Distribution and Change. In 2014, grassland was the largest ecosystem in the NKEFZ, the area proportion was $41.12 \%$, and then the forest area proportion was $22.59 \%$. Settlement had the minimum area, whose proportion was only $0.23 \%$. During $2000-2014$, the area proportion of forest decreased from $23.41 \%$ to $22.59 \%$. Grassland decreased from $42.24 \%$ to $41.12 \%$. Water body and wetland decreased from $3.71 \%$ to $5.45 \%$. On the contrary, farmland increased slightly from $8.36 \%$ to $8.40 \%$. Settlement and bare land showed little change in the NKEFZ (Figure 2).

In the 25 ecological function zones, the TI located at the southernmost tip of China had the largest forest area proportion of $83.10 \%$. While the DT had the lowest forest area proportion in western China, the number is only $0.03 \%$. However, the grassland area proportion in the DT is the highest in the 25 zones. Instead, this number is only $2.30 \%$ in the FCM. In general, the natural vegetation area proportion maximum is $98.22 \%$ in the GR; the minimum value is $23.51 \%$ in the GA (Figure 3).

The main ecosystems in different NKEFZ types were not entirely the same. In the water conservation types zones, the main ecosystems are grassland and forest, and the mean area proportions were $36.82 \%$ and $33.55 \%$, such as the GR and FCM. In the water and soil conservation type zones, forest is the main ecosystem with mean area proportion of $46.94 \%$. The representative zones were the TA and KY. Grassland

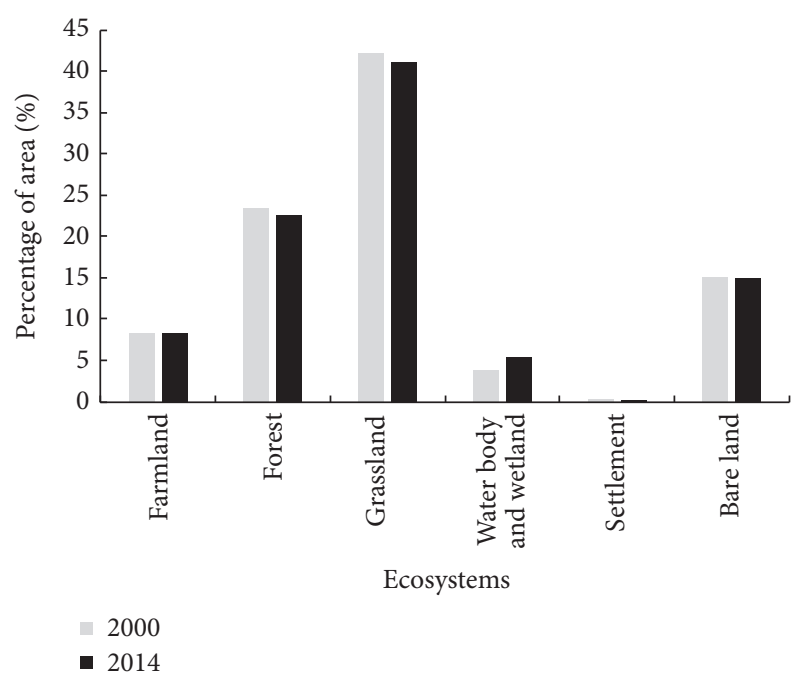

FIGURE 2: The area proportion change of ecosystems in NKEFZ.

was also the largest ecosystem in the wind break and sand fixation type zones, with mean area proportion of $51.02 \%$. The typical zones were the GB and HD. The biodiversity maintenance type zones mainly included forest and grassland ecosystems with mean area proportion of $46.07 \%$ and $26.79 \%$, respectively. The DT and TI were the most representative.

5.2. Vegetation Growth and Change. The normalized difference vegetation index (NDVI) is used to indicate the vegetation growth status. In spite of the close relationship between NDVI and climate change, NDVI can also reflect the characteristics of human activities [27], such as vegetation restoration projects. Statistical analysis showed that the mean NDVI was 0.4307 . The TI had the highest NDVI value of 0.8211 in the NKEFZ, while the GA had the lowest NDVI value of 0.0681 . In the aspect of function zone type, biodiversity maintenance type zones had the highest NDVI value of 0.5536 and wind break and sand fixation type zones had the lowest NDVI values of 0.1926 (Figure 4).

During 2000-2014, NDVI values showed a slight decrease trend in the MA, FT, and FY, while in the other 22 zones the NDVI values were increased. It is worth noting that there was significant increase in the HP, BQ, TA, and BW $(P<0.001)$. For example, the NDVI increased from 0.6712 in 2000 to 0.7253 in 2014 in the BW. In the 25 function zones, the main ecosystem with NDVI increased was grassland. In the aspect of function zone type, biodiversity maintenance and water and soil conservation type zones showed obvious increasing trend in NDVI, and the change rates were 0.0030 and 0.0012 per year, respectively. These values were 0.0011 and $0.0007 \mathrm{per}$ year, respectively, in wind break and sand fixation and water conservation type zones. The mean NDVI of the NKEFZ had showed a significant increase from 0.4184 in 2000 to 0.4405 in $2014(P<0.001)$ (Figure 5).

5.3. Water Conservation Simulation and Evaluation. The mean WR of observation was $174.71 \mathrm{~mm}$ in the NKEFZ. The TI had the maximum of WR of observation value 




Farmland

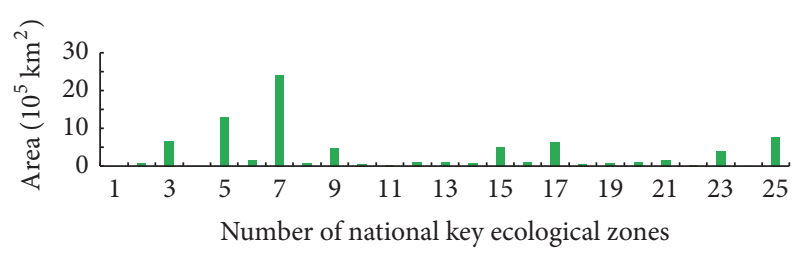

- Forest

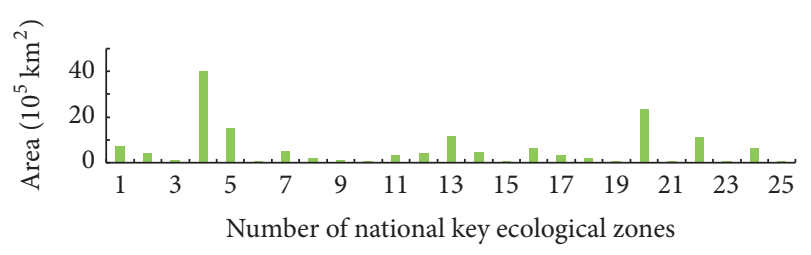

Grassland

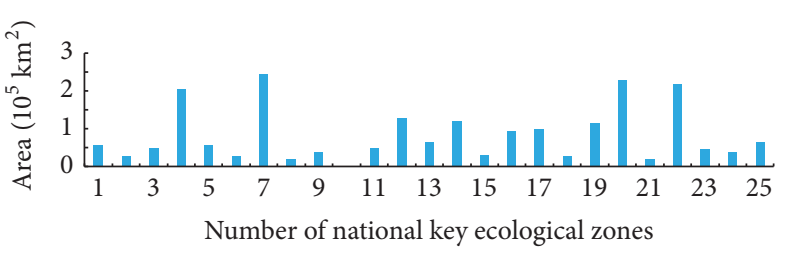

Water body and wetland


Bare land

FIGURE 3: Area of each ecosystem in NKEFZ (the number can refer to Figure 1).

with $985.23 \mathrm{~mm}$. In the GA, WR of observation value was $-101.21 \mathrm{~mm}$. In the aspect of function zone type, water and soil conservation and biodiversity maintenance type zones had the largest WR of observation value of $286.19 \mathrm{~mm}$ and $286.13 \mathrm{~mm}$, respectively. Then water conservation type zones' mean value was $120.69 \mathrm{~mm}$. The minimum value of WR of

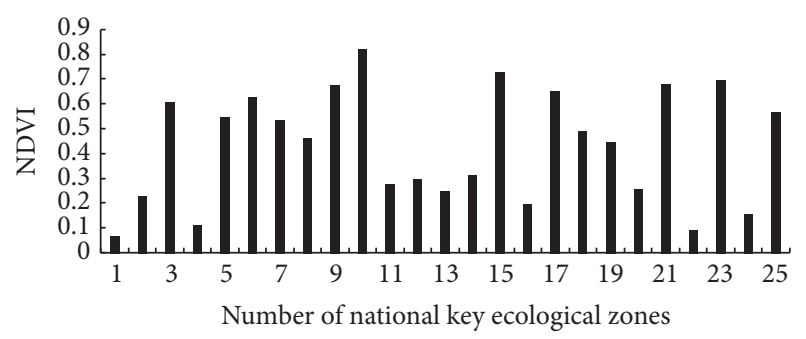

FIgURE 4: Mean values of NDVI in NKEFZ (the number can refer to Figure 1).

observation was in wind break and sand fixation type zones (Figure 6).

There are obvious spatial differences of WR of observation between the north and the south in the NKEFZ. And the value of the south was higher, such as the upper and middle reaches of the Yangtze River Basin (Figures 7(a) and 7(b)). The main reason was the obvious different vegetation types and precipitation.

During 2000-2014, WR of observation change indicated that water conservation was increased obviously in the GS dominated by grassland and the FM dominated by forest, while the water conservation decreased in the zones located in the south of the Yangtze River area. In arid and semiarid zones over northwest China, water conservation had a slight increase on the whole. However, what was unusual was that the WR of simulation change had showed opposite trend with the WR of observation in some zones, such as the HP and GH (Figures 7(c) and 7(d)). WR of simulation decreased year by year. The main reason was that the surface vegetation coverage increased gradually, so the evapotranspiration increased accordingly (Figure 5).

Figure 8 depicted the temporal variation of water conservation and precipitation in different zones. The results showed that the mean WR of observation increased slightly from $192.34 \mathrm{~mm}$ to $198.98 \mathrm{~mm}$ during $2000-2014(P<0.2)$ and had consistent change with precipitation. Specifically, there were six zones of water conservation showing a slight decrease. The zones were the MA, FT, KY, FNM, TA, and DR. The rest of the 19 zones showed an increasing trend. The GS had relatively significantly increased with water conservation from $-199.45 \mathrm{~mm}$ in 2000 to $40.82 \mathrm{~mm}$ in $2014(P<0.1)$. Other zones showed increasing volatility. Contrary to NDVI change, water conservation mainly increased in grassland ecosystem. In the aspect of function zone type, water conservation had the largest increase in water conservation type zones. The mean change rate was $4.01 \mathrm{~mm} /$ year. Secondly, the change rates were $3.83 \mathrm{~mm} /$ year in biodiversity maintenance type zones and $3.20 \mathrm{~mm} /$ year in wind break and sand fixation type zones, respectively. Instead, water conservation showed a trend of decrease in water and soil conservation type zones and the change rate was $0.54 \mathrm{~mm} /$ year.

However, the WR of simulation showed a slight decrease from $185.18 \mathrm{~mm}$ to $174.70 \mathrm{~mm}$ during 2000-2014 $(P<0.5)$. Compared with the observation results, WR of simulation had no interference from precipitation change. This could also reduce the uncertainty of climate change and reflect the 

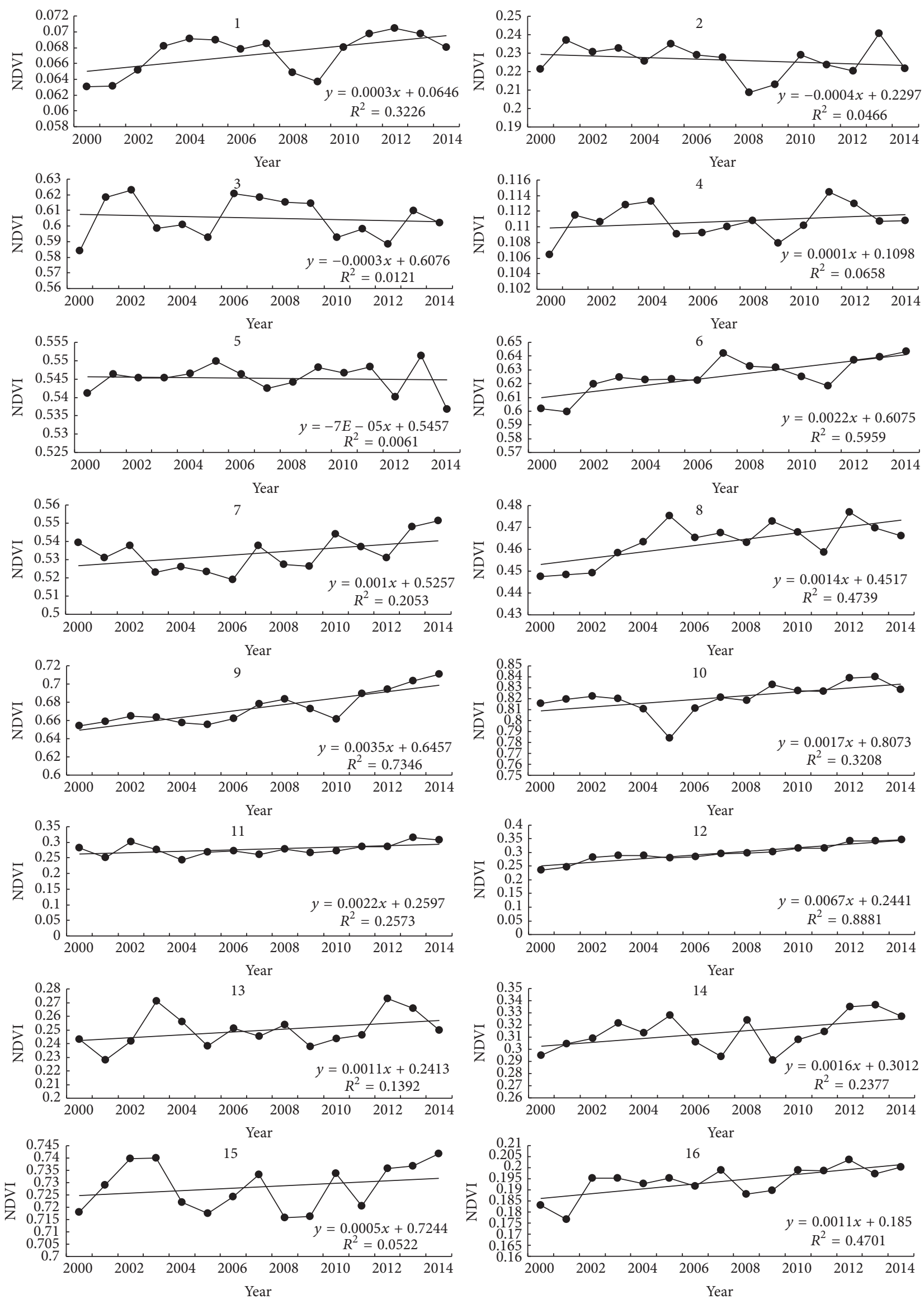

Figure 5: Continued. 

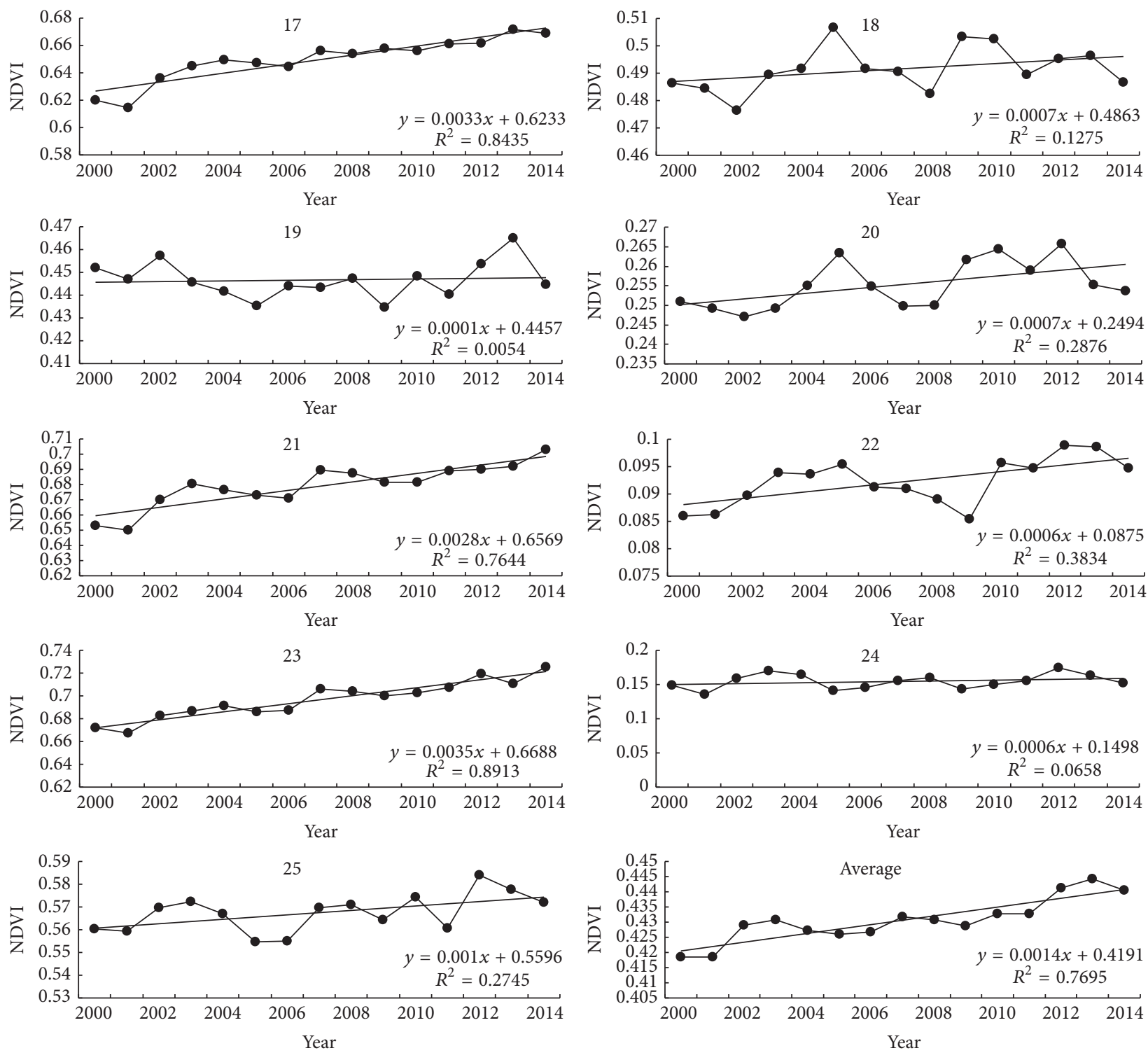

FIGURE 5: Statistic features of mean values of NDVI in NKEFZ from 2000 to 2014.

change of underlying surface. In the 25 zones, there were 16 zones showing a decrease in water conservation, which was consistent with Figure 7 . The most significant change is in the HP $(P<0.06)$. The surface vegetation improvement was the main reason.

\section{Discussions}

Regional ecological service assessment was affected by climate change and human activities. In recent years, many protection projects and measures were carried out and played an active role in ecosystem restoration in China [4], such as the Grain to Green Program (GTGP), Natural Forest Protection (NFP), Returning Rangeland to Grassland Program (RRGP), and sand control engineering. As a result, the vegetation evapotranspiration increased gradually, and WR of simulation showed a decreasing trend. However, because

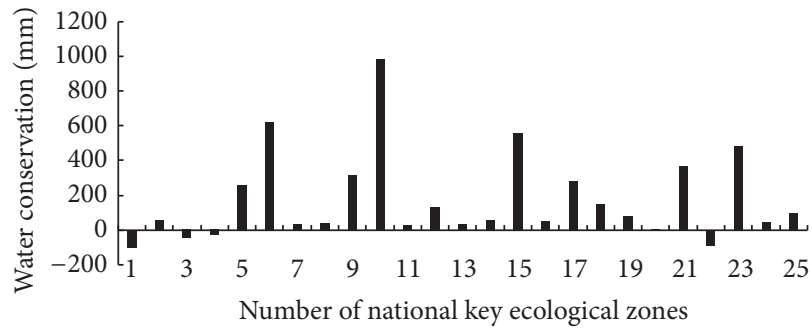

FIGURE 6: Mean water conservation of observation in NKEFZ (the number can refer to Figure 1).

of the increase of precipitation, WR of observation displays an increasing trend. Therefore, in future research, before the evaluation of water conservation, the models and hypothesis should be determined firstly. Also the climate factors and 


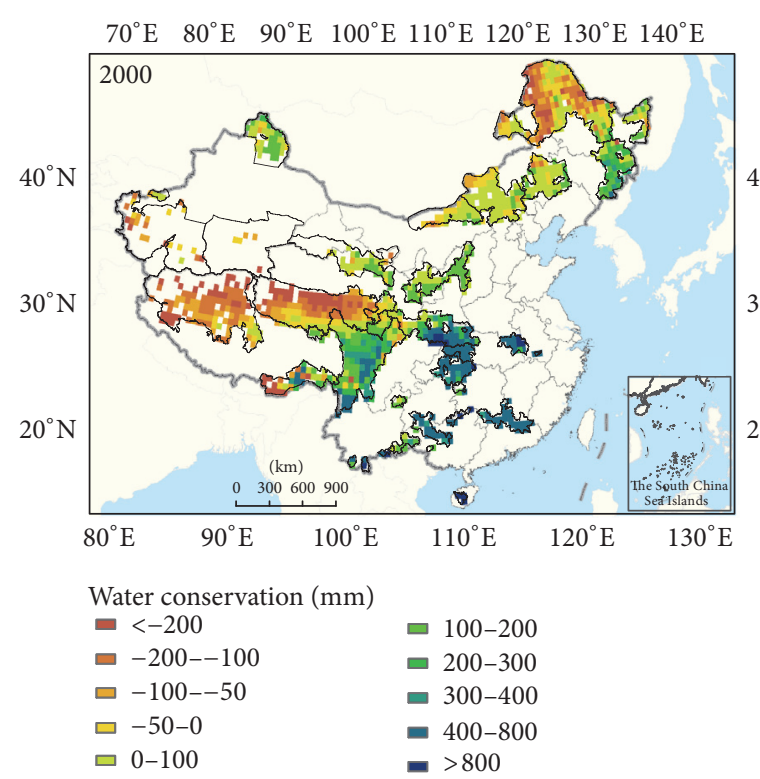

(a)

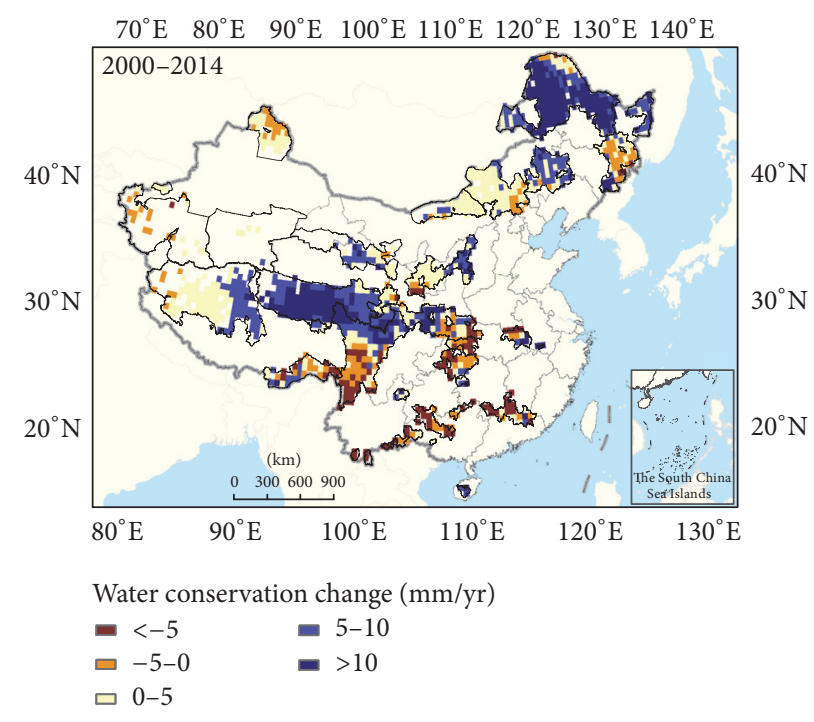

(c)

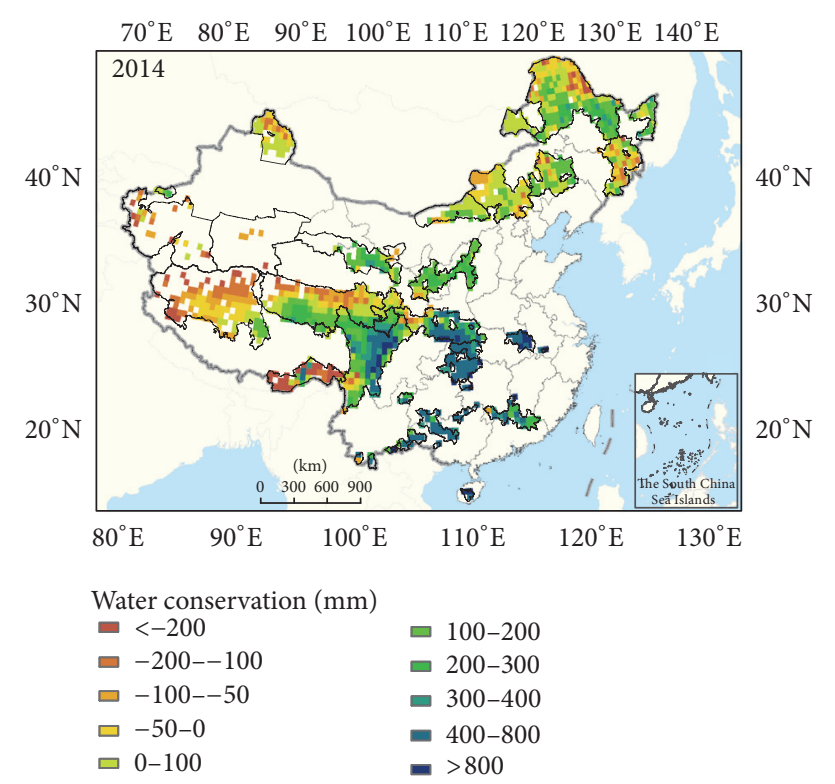

(b)



(d)

FIGURE 7: Spatial distribution and change of water conservation in NKEFZ ((a) WR of observation in the NKEFZ of 2000; (b) WR of observation in the NKEFZ of 2014; (c) WR change of observation in the NKEFZ; (d) WR change of simulation in the NKEFZ).

human disturbance should be separated for calculation. Only in this way will assessment results be accurate and credible, and ecology managers and government policy makers could develop targeted management measures and implement different ecological protection projects for ecological function zones.

Regional ecological function assessment should also consider the different features of the underlying surface [28]. It is necessary to characterize the differences of ecological function variation at a local scale. In GS, WR of observation showed increase trend during 2000-2014. Figure 8 also indicated that WR of observation had been negative before 2007 and became positive after 2007. These two stages of change had coincided with the approval time of plan named "the overall planning of ecological protection and construction in Qinghai Three-River Headwater Region nature reserve region." The WR of simulation showed different change features between the eastern and western GS. The possible reason was that the ecological protection projects have promoted vegetation restoration and increased evapotranspiration in the eastern region. However, in the western region, there were the most serious grassland degradation and a large number of secondary bare lands. Saturated water content of soil in this region was only half of the eastern region. Ecological protection projects could not prevent the water content decrease. Accordingly, there was less contribution of vegetation on underlying surface evapotranspiration. Moreover, water and swamps tended to dry in many ways in these regions [29]. 

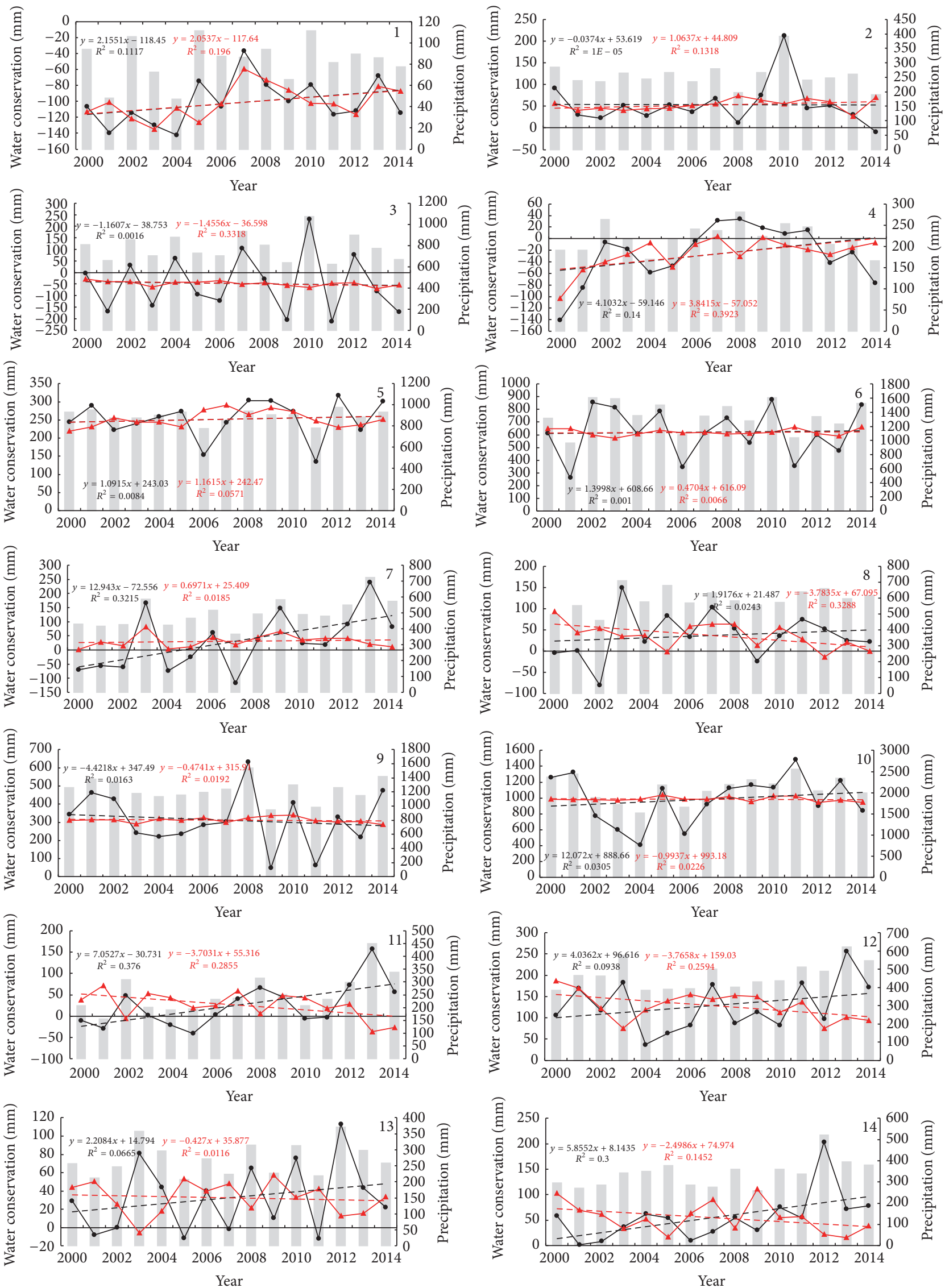

FIgURe 8: Continued. 

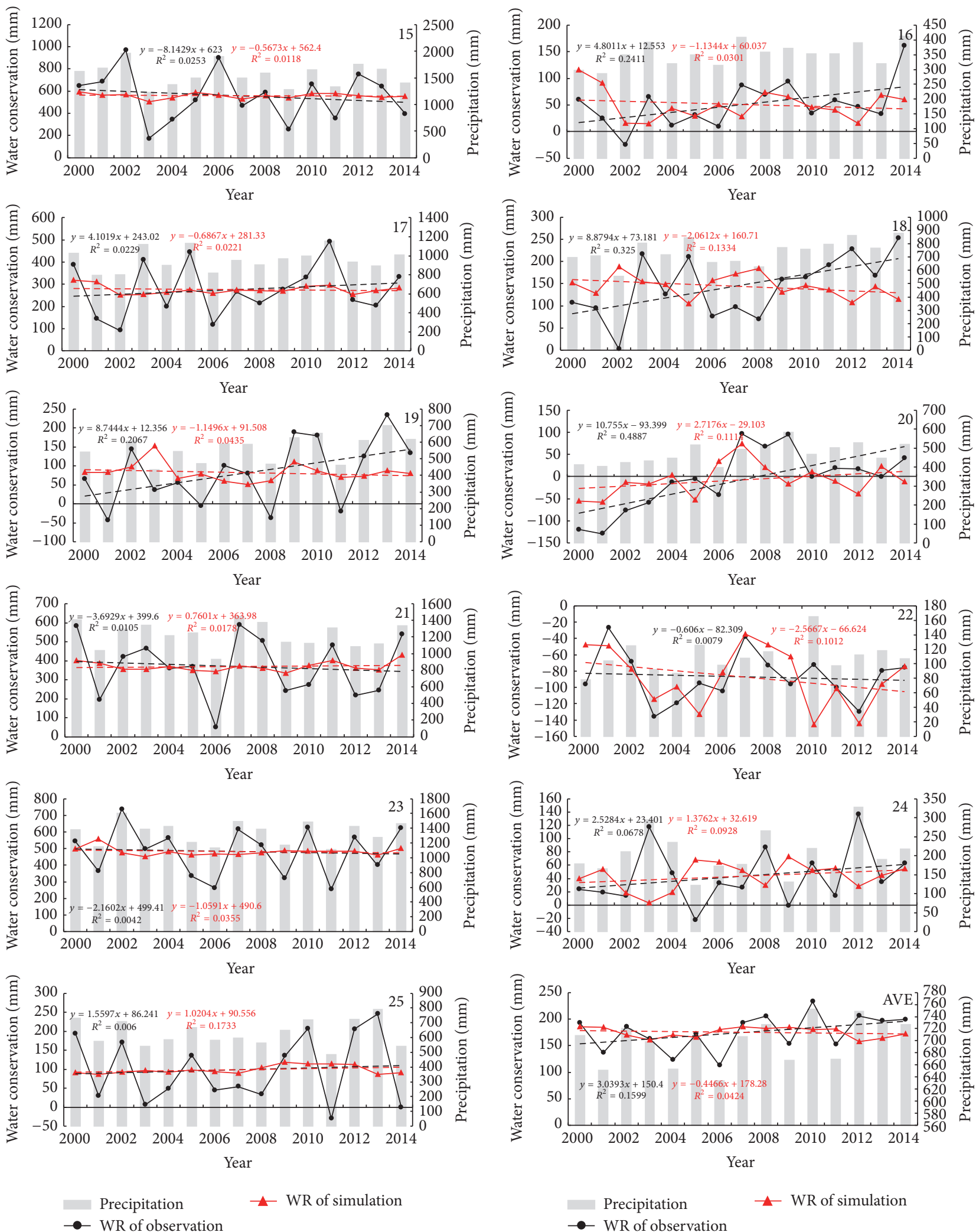

$-\quad \rightarrow$ WR of simulation

$\rightarrow$ WR of observation

FIGURE 8: Mean water conservation and annual precipitation change in NKEFZ. 
Thus the evapotranspiration decreased and WR of simulation increased instead. However, further research would need more observation data and model simulation to reveal details of reasons of water conservation change on a local scale.

In the arid and semiarid area, evaluation of ecosystem service change caused by ecological protected projects implementation needs to take into account complex surface change. The reason is that maybe more net radiation is absorbed by the restoration vegetation [30]. In the process of energy distribution, more net radiation not only is beneficial to the growth of vegetation, but also could improve surface temperature and then it increases evapotranspiration. Finally, water conservation may be impacted. Therefore, coupled with more ecological parameters, developing land surface process models including energy balance principle is needed to evaluate ecosystem service scientifically in regional scale and provide references for ecological policy makers.

\section{Conclusions}

(1) The natural vegetation, such as forest and grassland, was the main ecosystem in the NKEFZ. Grassland ecosystem is dominant and largest in area, accounting for $41.12 \%$ of the total area. Then forest area proportion was $22.59 \%$. Settlement was minimum in area, whose proportion was only $0.23 \%$. From 2000 to 2014, area proportion of forest and grassland decreased by $0.82 \%$ and $1.12 \%$, respectively. Farmland increased by about $0.04 \%$, which suggested that land reclamation and other human activities were still increasing.

(2) Vegetation was growing well as a whole in the NKEFZ. Mean NDVI was 0.4307. Biodiversity maintenance type zones had the highest NDVI value of 0.5536 and wind break and sand fixation type zones had the lowest NDVI values of 0.1926. During 2000-2014, the mean NDVI of the NKEFZ had showed a significant increase from 0.4184 to $0.4405(P<$ $0.001)$. On the other hand, NDVI values showed a slight decrease trend in the MA, FT, and FY. Nevertheless, NDVI values were increased in other zones. There was significant increase in the HP, BQ, TA, and BW $(P<0.001)$.

(3) During 2000-2014, mean WR of observation was $174.71 \mathrm{~mm}$ in the NKEFZ. The TI had the maximum of WR of observation value with $985.23 \mathrm{~mm}$. In the GA, WR of observation value was $-101.21 \mathrm{~mm}$. There are obvious spatial differences of WR of observation between the north and the south in the NKEFZ. WR of observation value of the south was higher, such as the upper and middle reaches of the Yangtze River Basin. Comparing two kinds of water conservation scheme, mean WR of observation increased slightly from $192.34 \mathrm{~mm}$ to $198.98 \mathrm{~mm}$ during 2000-2014 $(P<$ 0.2 ). It was mainly located in grassland. However, the WR of simulation showed a slight decrease from $185.18 \mathrm{~mm}$ to $174.70 \mathrm{~mm}$ during 2000-2014 $(P<0.5)$. WR of simulation reduced the uncertainty of climate change and reflected the change of underlying surface. In the important region of ecological protected projects implementation, such as the HP, evapotranspiration increased obviously with improvement of vegetation. Furthermore, WR of simulation showed significant decrease $(P<0.6)$. WR of observation increased mainly because of the increased precipitation.

\section{Competing Interests}

The authors declare that there is no conflict of interests regarding the publication of this paper.

\section{Acknowledgments}

This research was supported by the Major State Science Research Development Program of China (Grant ID: 2016YFC0500206).

\section{References}

[1] H. El Kateb, H. Zhang, P. Zhang, and R. Mosandl, "Soil erosion and surface runoff on different vegetation covers and slope gradients: a field experiment in Southern Shaanxi Province, China," Catena, vol. 105, pp. 1-10, 2013.

[2] D. Teka, B. Wesemael, V. Vanacker et al., "Evaluating the performance of reservoirs in semi-arid catchments of Tigray: tradeoff between water harvesting and soil and water conservation," Catena, vol. 110, pp. 146-154, 2013.

[3] M. Lee, G. Park, M. Park, J. Park, J. Lee, and S. Kim, "Evaluation of non-point source pollution reduction by applying Best Management Practices using a SWAT model and QuickBird high resolution satellite imagery," Journal of Environmental Sciences, vol. 22, no. 6, pp. 826-833, 2010.

[4] X. M. Feng, G. Sun, B. J. Fu, C. H. Su, Y. Liu, and H. Lamparski, "Regional effects of vegetation restoration on water yield across the Loess Plateau, China," Hydrology and Earth System Sciences, vol. 16, no. 8, pp. 2617-2628, 2012.

[5] X. H. Wei, G. Sun, J. M. Vose, K. Otsuki, Z. Zhang, and K. Smetterm, "Forest ecohydrological processes in a changing environment," Ecohydrology, vol. 4, no. 2, pp. 143-145, 2011.

[6] The State Council of the People's Republic of China, Major Function-Oriented Zone Planning in China, The State Council of the People's Republic of China, Beijing, China, 2010 (Chinese).

[7] Ministry of Environmental Protection, China Ecological Function Regionalization, Ministry of Environmental Protection, 2008 (Chinese).

[8] J. Fan, "Draft of major function oriented zoning of China," Acta Geographica Sinica, vol. 70, no. 2, pp. 186-201, 2015 (Chinese).

[9] Ministry of Environmental Protection, The Delineation of Ecological Protection Red Technology Guide, Ministry of Environmental Protection, 2015 (Chinese).

[10] G. P. Li and W. B. Zhang, "Study on the transfer payment differentiation contract of national key ecological function zone," Modern Economic Sciencem, vol. 37, no. 6, pp. 92-125, 2015 (Chinese).

[11] G. P. Li and X. Li, "Allocation mechanism of national key ecological function area's transfer paymen," China Population, Resources and Environment, vol. 24, no. 5, pp. 124-130, 2015 (Chinese).

[12] H. Lin, C. Wei, W. Dan, G. Guoli, and Z. Guosong, "Assessment on the changing conditions of ecosystems in key ecological function regions in China," Chinese Journal of Applied Ecology, vol. 26, no. 9, pp. 2758-2766, 2015 (Chinese).

[13] Q. Wang, P. Hou, F. Zhang, and C. Wang, "Integrated monitoring and assessment framework of regional ecosystem under the global climate change background," Advances in Meteorology, vol. 2014, Article ID 896453, 8 pages, 2014.

[14] J. Liu, H. Tian, M. Liu, D. Zhuang, J. M. Melillo, and Z. Zhang, "China's changing landscape during the 1990s: large-scale 
land transformations estimated with satellite data," Geophysical Research Letters, vol. 32, no. 2, Article ID L02405, 2005.

[15] J. Y. Liu, M. L. Liu, X. Z. Deng, D. F. Zhuang, Z. X. Zhang, and D. Luo, "The land use and land cover change database and its relative studies in China," Journal of Geographical Sciences, vol. 12, no. 3, pp. 275-282, 2002.

[16] J. Y. Liu, M. L. Liu, H. Q. Tian et al., "Spatial and temporal patterns of China's cropland during 1990-2000: an analysis based on Landsat TM data," Remote Sensing of Environment, vol. 98, no. 4, pp. 442-456, 2005.

[17] J. Liu, W. Kuang, Z. Zhang et al., "Spatiotemporal characteristics, patterns, and causes of land-use changes in China since the late 1980s," Journal of Geographical Sciences, vol. 24, no. 2, pp. 195-210, 2014.

[18] A. Huete, K. Didan, T. Miura, E. P. Rodriguez, X. Gao, and L. G. Ferreira, "Overview of the radiometric and biophysical performance of the MODIS vegetation indices," Remote Sensing of Environment, vol. 83, no. 1-2, pp. 195-213, 2002.

[19] A. Savitzky and M. J. E. Golay, "Smoothing and differentiation of data by simplified least squares procedures," Analytical Chemistry, vol. 36, no. 8, pp. 1627-1639, 1964.

[20] J. Chen, P. Jönsson, M. Tamura, Z. Gu, B. Matsushita, and L. Eklundh, "A simple method for reconstructing a high-quality NDVI time-series data set based on the Savitzky-Golay filter," Remote Sensing of Environment, vol. 91, no. 3-4, pp. 332-344, 2004.

[21] R. J. Donohue, M. L. Roderick, and T. R. McVicar, "On the importance of including vegetation dynamics in Budyko's hydrological model," Hydrology and Earth System Sciences, vol. 11, no. 2, pp. 983-995, 2007.

[22] G. Sun, G. Y. Zhou, Z. Q. Zhang, X. H. Wei, S. G. McNulty, and J. M. Vose, "Potential water yield reduction due to forestation across China," Journal of Hydrology, vol. 328, no. 3-4, pp. 548558, 2006.

[23] Q. Mu, F. A. Heinsch, M. Zhao, and S. W. Running, "Development of a global evapotranspiration algorithm based on MODIS and global meteorology data," Remote Sensing of Environment, vol. 111, no. 4, pp. 519-536, 2007.

[24] Q. Mu, M. Zhao, and S. W. Running, "Improvements to a MODIS global terrestrial evapotranspiration algorithm," Remote Sensing of Environment, vol. 115, no. 8, pp. 1781-1800, 2011.

[25] S. M. Liu, Z. W. Xu, Z. L. Zhu, Z. Z. Jia, and M. J. Zhu, "Measurements of evapotranspiration from eddy-covariance systems and large aperture scintillometers in the Hai River Basin, China," Journal of Hydrology, vol. 487, pp. 24-38, 2013.

[26] Y. Chen, J. Xia, S. Liang et al., "Comparison of satellitebased evapotranspiration models over terrestrial ecosystems in China," Remote Sensing of Environment, vol. 140, pp. 279-293, 2014.

[27] P. Hou, Q. Wang, G. Cao, C. Wang, Z. Zhan, and B. Yang, "Sensitivity analyses of different vegetations responding to climate change in inland river basin of China," Journal of Geographical Sciences, vol. 22, no. 3, pp. 387-406, 2012.

[28] P. Hou, Q. Wang, W. M. Shen, J. Zhai, H. M. Liu, and M. Yang, "Progress of integrated ecosystem assessment: concept, framework and challenges," Geographical Research, vol. 34, no. 10, pp. 1809-1823, 2015.

[29] J. Liu, X. Xu, and Q. Shao, "Grassland degradation in the "ThreeRiver Headwaters' region, qinghai province," Journal of Geographical Sciences, vol. 18, no. 3, pp. 259-273, 2008.
[30] J. Zhai, R. Liu, J. Liu, L. Huang, and Y. Qin, "Human-induced landcover changes drive a diminution of land surface albedo in the Loess Plateau (China)," Remote Sensing, vol. 7, no. 3, pp. 2926-2941, 2015. 

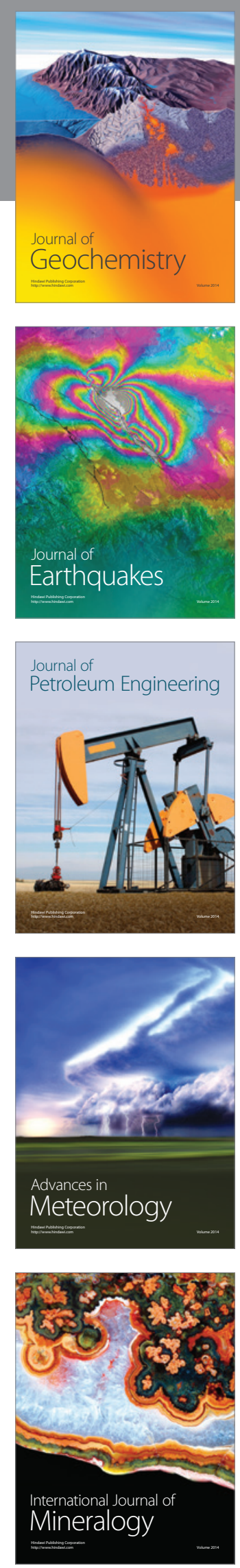
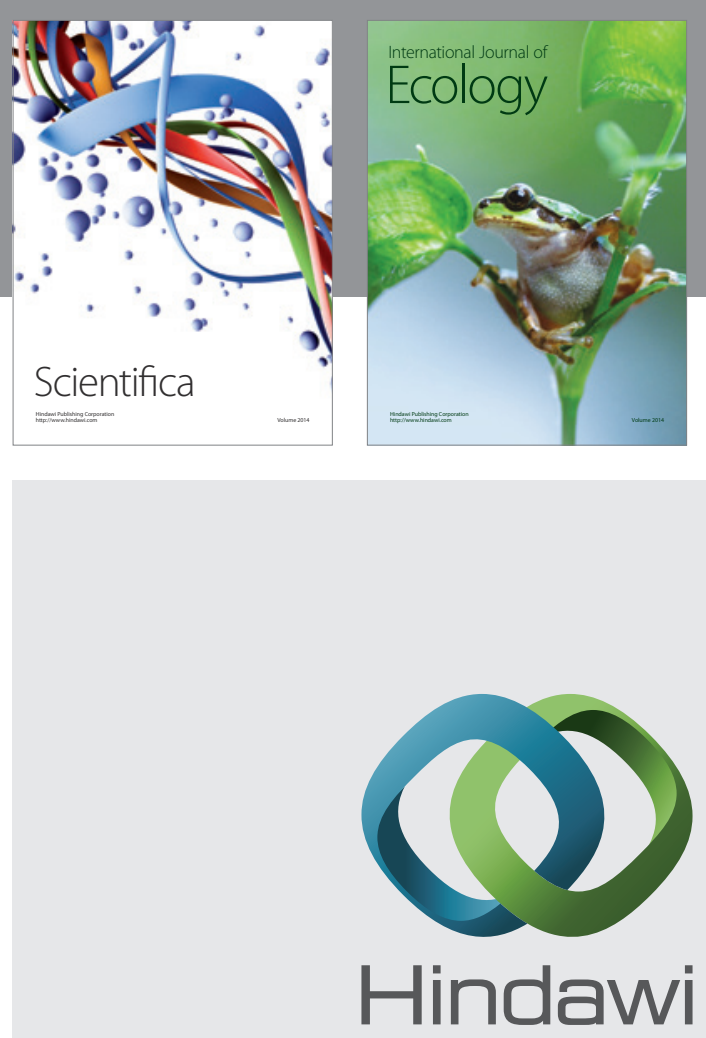

Submit your manuscripts at

http://www.hindawi.com
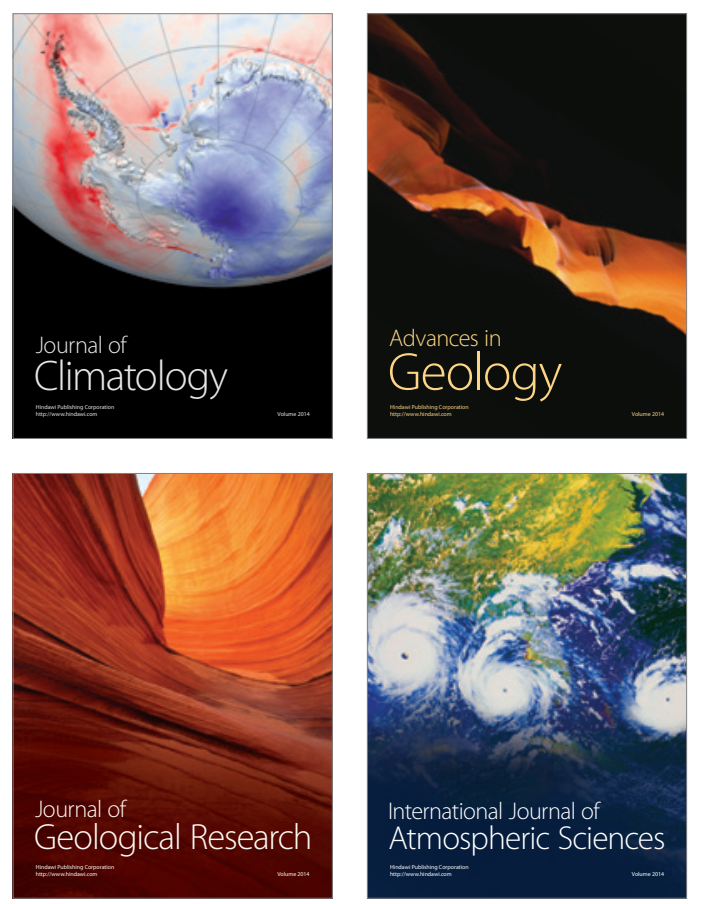

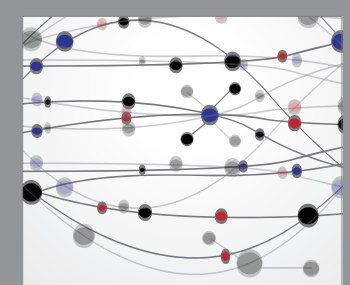

The Scientific

\section{World Journal}
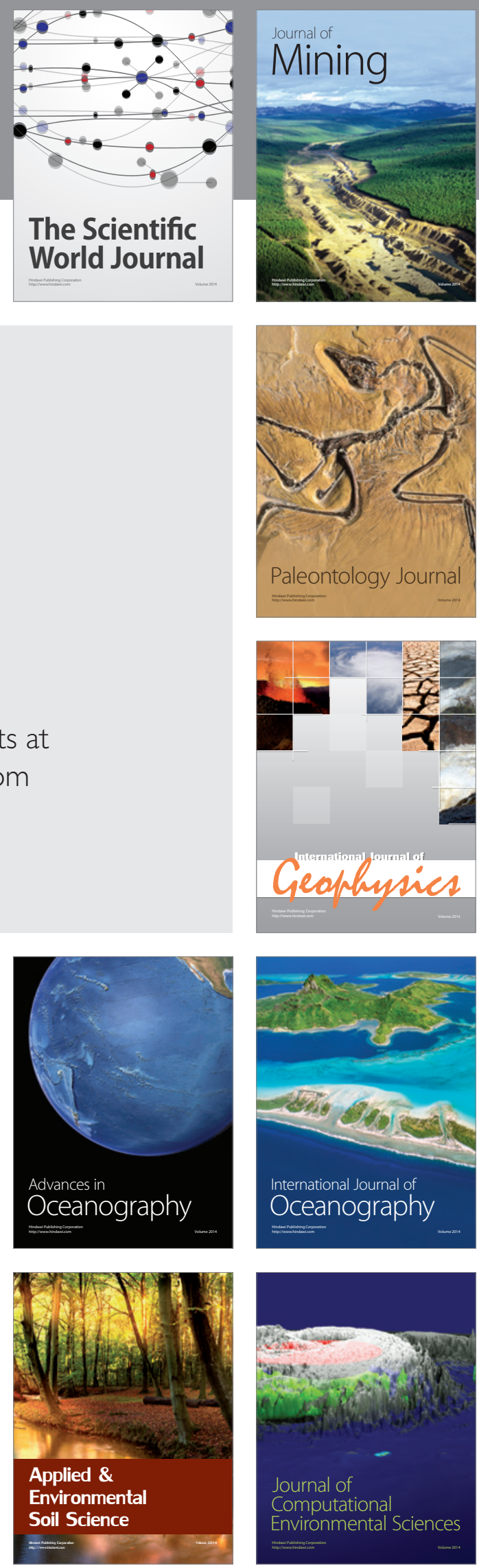